\title{
Diagnostic and Predictive Value of Some Tumor Markers in the Diagnosis and Follow Up of Patients with Hepatocellular Carcinoma
}

\author{
Ghada A. Abdel-Aleem, Ayman A. Wagih, *Sabry Abousaif, \\ **Mona Abdel-Azem \\ Departments of Medical Biochemistry, *Tropical, **Pathology, \\ Faculty of Medicine, Tanta University
}

\begin{abstract}
Early detection of hepatocellular carcinoma (HCC) is essential for successful treatment. Although the role of alpha fetoprotein (AFP) in the diagnosis of advanced HCC is well recognized, at least one third of small HCCs and 15-20\% of advanced HCC will be missed unless another diagnostic tool is used. Thus, new serologic markers with sufficient sensitivity and specificity are required. In the present study, we aimed at evaluating the diagnostic and prognostic role of AFP, protein induced by vitamin $K$ absence or antagonist(P1VKA-II), vascular endothelial growth factor (VEGF), sialic acid, alpha-L-fucosidase (AFU) and transforming growth factor-beta 1 (TGF- $\beta 1$ ) in the diagnosis and follow up of Egyptian patients with hepatocellular carcinoma in an attempt to find a tumor marker with a reasonable sensitivity and specificity for diagnosis of HCC and monitoring patients after therapy. The study was conducted on 4 selected groups of patients and a control group. Group I included 10 patients with liver cirrhosis. Group II consisted of 10 patients with benign hepatic focal lesions. Group III included 10 HCC patients without distant metastasis and group IV included 10 HCC patients presenting with metastasis. Ten apparently healthy age and sex matched subjects were also included and served as control group. AFP, sialic acid, alpha-L-fucosidase (AFU), VEGF, PIVKA-II and TGF- $\beta 1$ were determined in the blood of five studied groups. The sensitivity and specificity of the tumor markers were calculated and compared. Significant differences in the median blood levels of AFP, PIVKA-II, VEGF, sialic acid, TGF- $\beta 1$ and alpha-Lfucosidase activity (AFU) were found on comparing the HCC groups (with and without metastasis) with the other groups. The median blood levels of PIVKA-II, $\alpha$ fetoprotein level, sialic acid and AFU activity were lower in the HCC group without metastasis compared to that with metastasis $(p<0.001)$. On the other hand, the median serum VEGF level was higher in the HCC group without metastasis compared to that of the HCC group with distant metastasis $(p<0.001)$. Serum TGF- $\beta 1$ level did not vary significantly between both groups (with and without metastasis) ( $p>0.05)$. There were significant lower median blood levels of all parameters in HCC patients without metastasis after ablation therapy compared to pretreatment levels. Combined determination of serological markers could be used as a highly valuable tool for screening and diagnosis of HCC as combination of these markers improved their sensitivity and specificity. They could also be used as prognostic markers decreasing the need for more invasive procedures.
\end{abstract}




\section{INTRODUCTION}

Hepatocellular carcinoma (HCC) is one of the most common malignant neoplasms. It is associated closely with cirrhosis and its prognosis is very poor because the diagnosis is generally late, when HCC presents with clinical symptoms, the tumor is usually advanced and the patient has few therapeutic options ${ }^{1}$. Therefore, early detection is important in the management of that type of cancer. Advanced imaging modalities have been used for screening $\mathrm{HCC}^{2}$ and several tumor markers have been recently investigated in HCC for assessing diagnosis, and monitoring patients with diagnosed disease ${ }^{3}$. Although the role of alpha fetoprotein (AFP) in the diagnosis of advanced HCC is well recognized, at least one third of small HCC and 15 - 20\% of advanced HCC will be missed unless another diagnostic tool is used. Furthermore, AFP may be elevated in non-malignant liver diseases ${ }^{4}$.

Protein induced by vitamin $\mathrm{K}$ absence or antagonist (PIVKA-II) is a tumor marker complementary to AFP in the diagnosis of $\mathrm{HCC}^{5}$. Tumor progression is angiogenesis dependent and vascular endothelial growth factor (VEGF) is a key growth factor in that process. It has been suggested that serum VEGF level may be useful as a biological marker of tumor invasiveness and a prognostic factor in HCC $^{6}$. Transforming growth factorß1 (TGF- $\beta 1$ ) is a potent growth inhibitor of normal hepatocytes and hepatoma cells that induces apoptosis in these cells. TGF- $\beta 1$ is highly expressed in many malignant tumors including $\mathrm{HCC}^{7-9}$.
Sialic acid is a member of a family of $\mathrm{N}$ - and $\mathrm{O}-$ acetyl derivatives of neuraminic acid and widely distributed in mammals. It usually occurs as a terminal component at the non-reducing end of carbohydrate chains of glycoproteins and glycolipids and is thought to be involved in receptor function, cell recognition and immunological reactions, it also accounts for $70-80 \%$ of the total surface negativity in a variety of cell types. Sialic acid is increased in the serum of tumorbearing humans and animals, and thus is a probable indicator of malignant tumor growth ${ }^{\mathbf{1 0}}$. Alpha-L-fucosidase (AFU) (E.C. 3.2.1.51) is a lysosomal enzyme present in all mammalian cells, involved in the catabolism of the fucose-containing glycoconjugates. ${ }^{11}$ In accordance with the study of Deugnier et al. (1984) ${ }^{11}$, the serum level of Alpha-L-fucosidase activity in patients with HCC was increased. This may be related to increased enzyme release by tumor cells ${ }^{12}$. AFU is an enzyme that catalyzes the chemical reaction of two substrates of this enzyme, $\alpha$-L-fucoside and $\mathrm{H}_{2} \mathrm{O}$, whereas its two products are L-fucose and alcohol ${ }^{11}$.

In the current study, we aimed at evaluating the diagnostic and prognostic role of AFP, PIVKA-II, VEGF, sialic acid, AFU and TGF- $\beta 1$ in the diagnosis and follow up of Egyptian patients with hepatocellular carcinoma in an attempt to find a tumor marker with a reasonable sensitivity and specificity for early diagnosis of HCC and monitoring patients after therapy. 


\section{PATIENTS \& METHODS}

The study was conducted on four selected groups of patients according to the clinical, laboratory, ultrasonographic and histopathological evaluation. The patients were selected from the Tropical Medicine Department, Tanta University Hospital, Tanta University. The included groups were as following:

Group I: 10 patients with liver cirrhosis (Child-Pugh class A).

Group II: 10 patients with benign hepatic focal lesions (HFL) as 3 cases with haemangioma, 3 cases with amoebic liver abscess, 2 cases with pyogenic liver abscess and 2 cases with hydatid cyst).

Group III: 10 HCC patients without metastasis.

Group IV: 10 HCC patients with distant metastasis.

Control Group: formed of 10 apparently healthy, age and sex matched subjects without any evidence of liver disease. All patients and control groups gave an informed consent to participate in the study.

\section{Exclusion criteria:}

1. Patients of Child-Pugh class B or C.

2. For HCC groups, patients with the following criteria were excluded:

a. Multiple focal lesions.

b. Portal vein thrombosis.

\section{Blood Samples}

Plasma samples: Six mls venous blood samples were taken from every patient and control subject, then immediately $1.8 \mathrm{~mL}$ of the blood sample was added to 0.2 sodium citrate in precalibrated tubes. The tubes containing the samples were centrifuged for 30 minutes at $3000 \mathrm{Xg}$ at $4^{\circ} \mathrm{C}$ and aliquots of the resulting plasma were transferred to polypropylene microtubes and stored at $-80^{\circ} \mathrm{C}$. Samples were thawed at room temperature at the time of assay measurement. Plasma samples were needed for PIVKA-II and TGF- $ß 1$ assay. It is very important to prevent platelets degranulation during the plasma collection for TGF- 11 assay because platelets constitute one of the main sources of TGF-ß1. So, the plasma was separated from the cells within 1 hour, centrifuged at $3000 \mathrm{Xg}$ for 30 minutes at $4^{\circ} \mathrm{C}$ to eliminate platelets, then the platelet-depleted plasma was collected.

Serum samples: The remaining peripheral venous blood sample were taken and transferred to disposable tubes. The tubes were promptly centrifuged at $4^{\circ} \mathrm{C}$, and aliquots of serum were immediately stored at $80^{\circ} \mathrm{C}$ until measurement. Serum samples were needed for other parameters assay.

\section{All patients were subjected to:}

- Clinical assessment by history taking and clinical examination.

- Laboratory evaluation including: Liver function tests (bilirubin, transaminases, alkaline phosphatase, prothrombin time and activity, serum total proteins and serum albumin).

- Serological examination for hydatid antibodies and amoebiasis.

- Hepatitis markers:

a) Hepatitis C virus (HCV): AntiHCV antibodies by third generation ELISA (Murex Diagnostic, England DAI 5LR) and PCR for HCV RNA. 
b)Hepatitis B virus (HBV): HBsAg, anti-HBcAb by ELISA (Sorin Biomedica) and PCR for HBV.

- Imaging techniques including:

a) abdominal ultrasonography with Doppler examination

b)Triphasic CT (abdomen and pelvis).

c) Patients with HCC were subjected to bone scan and MRI of brain, chest and abdomen to detect distant metastasis.

- Liver biopsy and histopathological evaluation for HCC patient groups.

- Cytological examination of fluid aspirated from infectious cysts.

- Assay of tumor markers: AFU activity was measured by modification of the method of Zielke et al. ${ }^{12}$. $10 \mu \mathrm{l}$ of serum were added to $50 \mu \mathrm{l}$ of the substrate mixture, $\quad \rho$-nitrophenyl- $\alpha$-Lfucopyranoside dissolved in phosphate buffer ( $\mathrm{pH}$ 5) and incubated for 1 hour at $37^{\circ} \mathrm{C}$. The reaction was stopped by adding 3.5 $\mathrm{ml}$ of stop buffer (pH 10.5) (15 mM sodium carbonate, $15 \mathrm{mM}$ glycine and $7.5 \mathrm{mM}$ sodium chloride). Blanks were prepared in the same way, but the incubation step was omitted. Absorbance of $\rho$ nitrophenol was read at $400 \mathrm{~nm}$. The change in the absorbance of the librated $\rho$-nitrophenol was directly proportional to the activity of $\alpha$-Lfucosidase enzyme and expressed as $\mathrm{nmol} / \mathrm{mL} / \mathrm{h}^{12}$. Sialic acid was measured by method of Hess et al. ${ }^{13}$ which depends on precipitation of serum proteins with trichloroacetic acid. The color resulting from condensation of N-acetylneuraminic acid with sulfuric-acetic acid reagent is read in the spectrophotometer at $530 \mathrm{~nm}$. $\alpha$ fetoprotein (AFP) was measured by quantitative sandwich ELISA using kits supplied by Biosource (Biosource International, California, USA) ${ }^{14}$, PIVKA-II was assayed by quantitative sandwich ELISA using kits supplied by Diagnostic Stago (Diagnostic Stago, France) $^{15}$, VEGF by competitive enzyme immunoassay using kits supplied by Cytimmune (Cytimmune Science INC. Maryland, USA) ${ }^{\mathbf{1 6}}$, TGF- $\beta 1$ by quantitative sandwich ELISA using kits supplied by Biosource (Biosource International, Inc.. California, USA) ${ }^{\mathbf{1 7}}$.

Hepatocellular carcinoma patients of Group III were treated using percutaneous ethanol injection (PEI) or percutaneous radiofrequency ablation (RF) according to the optimal protocol of percutaneous ablation therapy. PEI ablation was selected for treatment of HCC patients when a tumor satisfied the following criteria: (1) existing in a subcapsular location, (2) existing in a location adjacent to a major vessel and another organ (heart, gall bladder, stomach and bowel) and (3) demonstrating poor differentiation. Four patients (40\%) were treated by PEI with tumors $\leq 3 \mathrm{~cm}$ in diameter. $\mathrm{RF}$ ablation was selected for the cases with low risks of tumor seeding and hemorrhage. Six patients (60\%) were treated by RF ablation. No local tumor residues were found in all patients as assessed by contrast enhanced CT six months after the initial successful percutaneous ablation therapy (no vascularities could be recognized within the tumor by contrast enhanced CT). All the studied tumor markers were assayed again in patients group 
III six months after the initial ablation successful treatment.

Statistical analysis: Continuous variables are expressed as mean $\pm S D$ for normally distributed data and by median for non parametric data. Student t-test (paired, unpaired), paired t-test was used in comparing levels of the different parameters in patients group III before and after ablation therapy. Mann Whitney U test and Kruskall Wallis tests were used for analysis. Multiple receiver operating characteristic curves (ROC curves) were drawn to assess the validity of the tumor markers.

\section{RESULTS}

The age and sex of the different studied groups are shown in table1.
The 5 groups were comparable regarding age and sex. Ninety percent $(18 / 20)$ of HCC patients (with and without metastasis) were positive for anti-HCV and only 10\% (2/20) were HBsAg positive. Clinical presentations of the different studied groups are shown in table2. Table 3 shows the results of liver function tests in the studied groups. The mean values of total bilirubin and aspartate transaminase were significantly higher in liver cirrhosis and the two HCC groups (III, IV) than the benign HFL and the control groups $(p<0.05)$. The mean value of alkaline phosphatase was significantly higher in the two HCC groups (with and without metastasis) than the other groups $(\mathrm{p}<0.05)$.

Table 1: Age and sex of the different studied groups.

\begin{tabular}{|l|c|c|c|c|c|}
\hline \multirow{2}{*}{} & \multirow{2}{*}{ No } & \multicolumn{2}{|c|}{ Age } & \multicolumn{2}{c|}{ Sex } \\
\cline { 3 - 6 } & & $\begin{array}{c}\text { Range } \\
\text { (year) }\end{array}$ & $\begin{array}{c}\text { Mean } \pm \text { SD } \\
\text { (year) }\end{array}$ & Female & Male \\
\hline Control Group & 10 & $25-58$ & $42.1^{\mathbf{a}} \pm 8.6$ & $4(40 \%)$ & $6(60 \%)$ \\
\hline Group I & 10 & $28-51$ & $43.2^{\mathbf{a}} \pm 7.7$ & $2(20 \%)$ & $8(80 \%)$ \\
\hline Group II & 10 & $26-52$ & $46.35^{\mathbf{a}} \pm 9.6$ & $1(10 \%)$ & $9(90 \%)$ \\
\hline Group III & 10 & $32-60$ & $48.1^{\mathbf{a}} \pm 8.13$ & $3(30 \%)$ & $7(70 \%)$ \\
\hline Group IV & 10 & $43-60$ & $48.6^{\mathbf{a}} \pm 4.6$ & $2(20 \%)$ & $8(80 \%)$ \\
\hline
\end{tabular}

Groups bearing different initials are significantly different from each other. 
Table 2: Clinical presentation of the different studied groups

\begin{tabular}{|c|c|c|c|c|}
\hline & $\begin{array}{c}\text { Group I } \\
\text { n (\%) }\end{array}$ & $\begin{array}{c}\text { Group II } \\
\text { n (\%) }\end{array}$ & $\begin{array}{c}\text { Group III } \\
\text { n (\%) }\end{array}$ & $\begin{array}{c}\text { Group IV } \\
\text { n (\%) }\end{array}$ \\
\hline Rt. Hypochondrial pain & $2(20 \%)$ & $3(30 \%)$ & $9(90 \%)$ & $9(90 \%)$ \\
\hline Jaundice & $5(50 \%)$ & $1(10 \%)$ & $7(70 \%)$ & $8(80 \%)$ \\
\hline Hepatomegaly & $0(0 \%)$ & $0(0 \%)$ & $2(20 \%)$ & $5(50 \%)$ \\
\hline Splenomegaly & $6(60 \%)$ & $0(0 \%)$ & $6(60 \%)$ & $7(70 \%)$ \\
\hline Lower limb oedema & $6(60 \%)$ & $0(0 \%)$ & $7(70 \%)$ & $8(80 \%)$ \\
\hline Upper GIT bleeding & $0(0 \%)$ & $0(0 \%)$ & $1(10 \%)$ & $2(20 \%)$ \\
\hline Ascitis & $6(60 \%)$ & $0(0 \%)$ & $8(80 \%)$ & $9(90 \%)$ \\
\hline Bleeding tendency & $3(30 \%)$ & $0(0 \%)$ & $8(80 \%)$ & $9(90 \%)$ \\
\hline Coma & $3(30 \%)$ & $0(0 \%)$ & $6(60 \%)$ & 7 (70\%) \\
\hline Fever & $1(10 \%)$ & $3(30 \%)$ & $1(10 \%)$ & $1(10 \%)$ \\
\hline
\end{tabular}

Table 3: Liver function tests of the studied groups. Groups bearing different initials are significantly different from each other.

\begin{tabular}{|l|c|c|c|c|c|}
\hline & $\begin{array}{c}\text { Control } \\
\text { Group } \\
\text { mean } \pm \text { SD }\end{array}$ & $\begin{array}{c}\text { Group I } \\
\text { mean } \pm \text { SD }\end{array}$ & $\begin{array}{c}\text { Group II } \\
\text { mean } \pm \text { SD }\end{array}$ & $\begin{array}{c}\text { Group III } \\
\text { mean } \pm \text { SD }\end{array}$ & $\begin{array}{c}\text { Group IV } \\
\text { mean } \pm \text { SD }\end{array}$ \\
\hline Total bilirubin (mg/dl) & $0.73 \pm 0.3^{\mathbf{b}}$ & $2.03 \pm 0.53^{\mathbf{a}}$ & $0.66 \pm 0.25^{\mathbf{b}}$ & $2.51 \pm 2.95^{\mathbf{a}}$ & $5.83 \pm 11.94^{\mathbf{a}}$ \\
\hline $\begin{array}{l}\text { Aspartate } \\
\text { transaminase (U/L) }\end{array}$ & $19 \pm 4.1^{\mathbf{b}}$ & $89.1 \pm 93.6^{\mathbf{a}}$ & $25.7 \pm 13.1^{\mathbf{b}}$ & $105.4 \pm 50.9^{\mathbf{a}}$ & $109.8 \pm 56.3^{\mathbf{a}}$ \\
\hline $\begin{array}{l}\text { Alanine transaminase } \\
(\mathrm{U} / \mathrm{L})\end{array}$ & $25.5 \pm 8.5^{\mathbf{c}}$ & $36.8 \pm 14.3^{\mathbf{a}}$ & $25.1 \pm 8.9^{\mathbf{a}}$ & $63.5 \pm 23.9^{\mathbf{a}}$ & $72.8 \pm 54^{\mathbf{a}}$ \\
\hline $\begin{array}{l}\text { Alkaline phosphatase } \\
(\mathrm{U} / \mathrm{L})\end{array}$ & $104.9 \pm 38.9^{\mathbf{c}}$ & $172 \pm 183.6^{\mathbf{a}}$ & $165.8 \pm 32.4^{\mathbf{a}}$ & $372.9 \pm 305^{\mathbf{b}}$ & $456.2 \pm 276^{\mathbf{b}}$ \\
\hline Total proteins (g/dl) & $7.3 \pm 0.5^{\mathbf{b c}}$ & $6.6 \pm 0.6^{\mathbf{a}}$ & $7.5 \pm 0.6^{\mathbf{b}}$ & $7.1 \pm 0.7^{\mathbf{a c}}$ & $6.7 \pm 1.1^{\mathbf{b}}$ \\
\hline Albumin (g/dl) & $3.7 \pm 1.4^{\mathbf{b}}$ & $3.1 \pm 0.6^{\mathbf{a}}$ & $3.8 \pm 0.5^{\mathbf{b}}$ & $2.9 \pm 0.5^{\mathbf{a d c}}$ & $2.7 \pm 0.2^{\mathbf{c}}$ \\
\hline $\begin{array}{l}\text { Prothrombin } \\
\text { concentration \% }\end{array}$ & $91.5 \pm 5 . \%^{\mathbf{d}}$ & $78.7 \pm 5.8 \%^{\mathbf{a}}$ & $82.5 \pm 7.9 \%^{\mathbf{a}}$ & $68 \pm 16.2 \%^{\mathbf{b}}$ & $66.5 \pm 18.4 \% \mathbf{b}^{\mathbf{b}}$ \\
\hline
\end{tabular}

On ultrasonographic examination, $80 \%$ of group II, III and IV had a single focal lesion. Only $20 \%$ of the same groups had double lesions. The median blood levels of AFP, PIVKAII, VEGF, sialic acid, AFU and TGF$\beta 1$ in the five studied groups are presented in table 4. A statistically significant differences in the median blood levels of AFP, PIVKA-II, TGF- $\beta 1$, sialic acid, VEGF and AFU activity were observed on comparing the HCC groups (with and without metastasis) with the control, the benign HFL and the cirrhotic groups $(\mathrm{p}<0.001)$ (table 4).

On comparing the HCC group without metastasis (group III) with that with distant metastasis (group IV), it was found that the median 
blood levels of AFP, PIVKA-II, sialic acid and AFU activity were significantly higher in the latter group(group IV) than that in the former (group III) $(\mathrm{p}<0.001)$. On the other hand, the median serum VEGF level was significantly higher in the HCC group without metastasis (2580 $\mathrm{pg} / \mathrm{ml}$ ) when compared to the group with distant metastasis $(1840 \mathrm{pg} / \mathrm{ml})$ $(p<0.001)$. Plasma TGF- $\beta 1$ level did not vary significantly between both groups ( $>>0.05$ ) (Table 4).

Comparison of the median blood levels of AFP, PIVKA-II, TGF- $\beta 1$, VEGF, sialic acid and AFU activity in HCC patients without metastasis(group III) before and six months after percutaneous ablation therapy revealed a statistically highly significant lowering of all parameters after ablation therapy (Table 5). Multiple receiver operating characteristic curve (ROC) revealed that the area under the curve (AUC) for AFP, PIVKA-II, TGF- $\beta 1$, VEGF, AFU and sialic acid were 0.880 , $0.900,0.910,0.890,0.960$ and 0.760 respectively (Fig. 1).

For AFP, at a cut-off level of 28 $\mathrm{ng} / \mathrm{mL}$, the sensitivity was $80 \%$, the specificity $97 \%$, positive predictive value (PPV) 92.3\%, negative predictive value (NPV) $86.6 \%$ and the overall accuracy was 90\%. For PIVKA-II, at a cut-off level of 12.5 $\mathrm{mAU} / \mathrm{mL}$, the sensitivity was $80 \%$, specificity 97\%, PPV 96\%, NPV $86.9 \%$ and accuracy was $90 \%$. Concerning VEGF, at a cut-off level of $780 \mathrm{pg} / \mathrm{mL}$, the sensitivity was $96.7 \%$, specificity $85 \%$, PPV $82.4 \%$, NPV $97.1 \%$ and the accuracy was $90 \%$. For sialic acid, at a cut-off level of $90 \mathrm{mg} / \mathrm{dL}$ sensitivity was $80 \%$, specificity $78 \%$, PPV $72.7 \%$, NPV $77.7 \%$ and accuracy was $75 \%$. At a cut-off level of $443 \mathrm{nmol} / \mathrm{ml} / \mathrm{h}$ for AFU, the sensitivity was $80 \%$, the specificity was $90 \%$, PPV $81.8 \%$, NPV $88.8 \%$ and accuracy was $85 \%$. Lastly for TGF- $\beta 1$, at a cut-off level of $32.4 \mathrm{ng} / \mathrm{mL}$ sensitivity was $76.7 \%$, specificity 97\%, PPV 95.8\%, NPV $84.7 \%$ and accuracy was $88.5 \%$ (Table 6).

A negative correlation was detected between plasma PIVKA-II and serum VEGF ( $\mathrm{r}=-0.594, \mathrm{p}=$ 0.012 ) in the HCC groups (III and IV), but no statistically significant correlations were found between serum AFP and the other markers (AFU, sialic acid, VEGF, PIVKA-II and TGF- $\beta 1)(p=0.428,0.692,0.322$, 0.091 and 0.106 respectively) (Table 7). 
Table 4: The median values of AFP, PIVKA-II, TGF- 1 1, VEGF, sialic acid and $A F U$ in the five studied groups. Groups bearing different initials are significantly different from each other.

\begin{tabular}{|c|c|c|c|c|c|c|}
\hline & $\begin{array}{c}\text { Control } \\
\text { Group } \\
\mathbf{n}=10\end{array}$ & $\begin{array}{c}\text { Group I } \\
\mathbf{n}=10\end{array}$ & $\begin{array}{c}\text { Group II } \\
\mathbf{n}=\mathbf{1 0}\end{array}$ & $\begin{array}{c}\text { Group III } \\
\mathbf{n}=\mathbf{1 0}\end{array}$ & $\begin{array}{c}\text { Group IV } \\
\mathbf{n}=10\end{array}$ & $\begin{array}{c}\text { p- } \\
\text { value }\end{array}$ \\
\hline $\begin{array}{l}\text { AFP }(\mathrm{ng} / \mathrm{mL}) \\
\text { Median } \\
\text { Range }\end{array}$ & $\begin{array}{c}2.5^{\mathbf{a}} \\
1.3-3.4\end{array}$ & $\begin{array}{c}6^{\mathrm{a}} \\
4.1-9.8\end{array}$ & $\begin{array}{c}2.5^{\mathrm{a}} \\
1.4-3.9\end{array}$ & $\begin{array}{c}673^{\mathbf{b}} \\
290-916\end{array}$ & $\begin{array}{c}2217^{\mathrm{c}} \\
51.8-3015\end{array}$ & $<0.001$ \\
\hline $\begin{array}{l}\text { PIVKA-II }(\mathrm{mAU} / \mathrm{mL}) \\
\text { Median } \\
\text { Range }\end{array}$ & $\begin{array}{c}1.1^{\mathbf{a}} \\
0.4-2.6\end{array}$ & $\begin{array}{c}1.1^{\mathbf{a}} \\
0.8-2.1\end{array}$ & $\begin{array}{c}1.5^{\mathrm{a}} \\
1.1-2.5\end{array}$ & $\begin{array}{c}16.2^{\mathbf{b}} \\
12.7-21.0\end{array}$ & $\begin{array}{c}33.6^{\mathbf{c}} \\
25.6-53.2\end{array}$ & $<0.001$ \\
\hline $\begin{array}{l}\text { TGF } \beta 1(\mathrm{ng} / \mathrm{mL}) \\
\text { Median } \\
\text { Range }\end{array}$ & $\begin{array}{c}20.2^{\mathbf{a}} \\
17.1-22.4\end{array}$ & $\begin{array}{c}20.7^{\mathbf{a}} \\
11.8-26.7\end{array}$ & $\begin{array}{c}20.8^{\mathbf{a}} \\
15.6-26.3\end{array}$ & $\begin{array}{c}42.5^{\mathbf{b}} \\
37.5-50.7\end{array}$ & $\begin{array}{c}37.6^{\mathbf{b}} \\
27.9-44.5\end{array}$ & $<0.001$ \\
\hline $\begin{array}{l}\text { VEGF(pg/mL) } \\
\text { Median } \\
\text { Range }\end{array}$ & $\begin{array}{c}160^{\mathbf{a}} \\
70-210\end{array}$ & $\begin{array}{c}180^{\mathbf{a}} \\
80-960\end{array}$ & $\begin{array}{c}160^{\mathbf{a}} \\
100-520\end{array}$ & $\begin{array}{c}2580^{\mathbf{b}} \\
2140-2970\end{array}$ & $\begin{array}{c}1840^{\mathbf{c}} \\
1300-2310\end{array}$ & $<0.001$ \\
\hline $\begin{array}{l}\text { Sialic Acid(mg/dL) } \\
\text { Median } \\
\text { Range }\end{array}$ & $\begin{array}{c}61^{\mathrm{a}} \\
59.1-109.5 \\
\end{array}$ & $\begin{array}{c}63^{\mathbf{a}} \\
59.9-118.1 \\
\end{array}$ & $\begin{array}{c}87^{\mathbf{a}} \\
73.1-147.2 \\
\end{array}$ & $\begin{array}{c}115^{\mathbf{b}} \\
84.3-219.8 \\
\end{array}$ & $\begin{array}{c}208^{\mathbf{c}} \\
175.1-265.3\end{array}$ & $<0.001$ \\
\hline $\begin{array}{l}\text { AFU(nmol/mL/h) } \\
\text { Median } \\
\text { Range }\end{array}$ & $\begin{array}{c}321^{\mathrm{a}} \\
210-448\end{array}$ & $\begin{array}{c}502^{\mathrm{a}} \\
466-758\end{array}$ & $\begin{array}{c}675^{\mathbf{a}} \\
625-831\end{array}$ & $\begin{array}{c}897^{\mathbf{b}} \\
403-1434\end{array}$ & $\begin{array}{c}1655^{\mathbf{c}} \\
1545-2058\end{array}$ & $<0.001$ \\
\hline
\end{tabular}

Table 5: The median value of AFP, VEGF, TGF- 1 1, PIVKA-II, sialic acid and AFU in the HCC group without metastasis (group III) before and after treatment

\begin{tabular}{|c|c|c|c|}
\hline 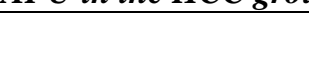 & Before treatment & After treatment & \\
\hline & $n=10$ & $n=10$ & p-value \\
\hline $\begin{array}{c}\boldsymbol{A F P}(\mathbf{n g} / \mathbf{m L}) \\
\text { Median } \\
\text { Range }\end{array}$ & $\begin{array}{c}673 \\
290-916\end{array}$ & $\begin{array}{c}31 \\
13.2-40.3\end{array}$ & $<0.001$ \\
\hline $\begin{array}{c}\text { PIVKA-II } \\
\text { (mAU/mL) } \\
\text { Median } \\
\text { Range } \\
\end{array}$ & $\begin{array}{c}16.2 \\
12.7-21.0\end{array}$ & $\begin{array}{c}4.1 \\
2-5.7 \\
\end{array}$ & $<0.05$ \\
\hline $\begin{array}{c}\text { TGF- } \boldsymbol{\beta} \mathbf{1}(\mathrm{ng} / \mathrm{mL}) \\
\text { Median } \\
\text { Range }\end{array}$ & $\begin{array}{c}42.5 \\
37.5-50.7\end{array}$ & $\begin{array}{c}17.5 \\
14.5-19.8\end{array}$ & $<0.05$ \\
\hline $\begin{array}{c}\text { VEGF }(\mathrm{pg} / \mathrm{mL}) \\
\text { Median } \\
\text { Range }\end{array}$ & $\begin{array}{c}2580 \\
2140-2970\end{array}$ & $\begin{array}{c}440 \\
250-540\end{array}$ & $<0.001$ \\
\hline $\begin{array}{c}\text { Sialic Acid }(\mathrm{mg} / \mathrm{dL}) \\
\text { Median } \\
\text { Range }\end{array}$ & $\begin{array}{c}115 \\
84.3-219.8\end{array}$ & $\begin{array}{c}29.1 \\
27.2-38.2\end{array}$ & $<0.001$ \\
\hline $\begin{array}{c}\text { AFU }(\mathrm{nmol} / \mathrm{ml} / \mathrm{h}) \\
\text { Median } \\
\text { Range }\end{array}$ & $\begin{array}{c}897 \\
403-1434\end{array}$ & $\begin{array}{c}409 \\
398-567\end{array}$ & $<0.001$ \\
\hline
\end{tabular}




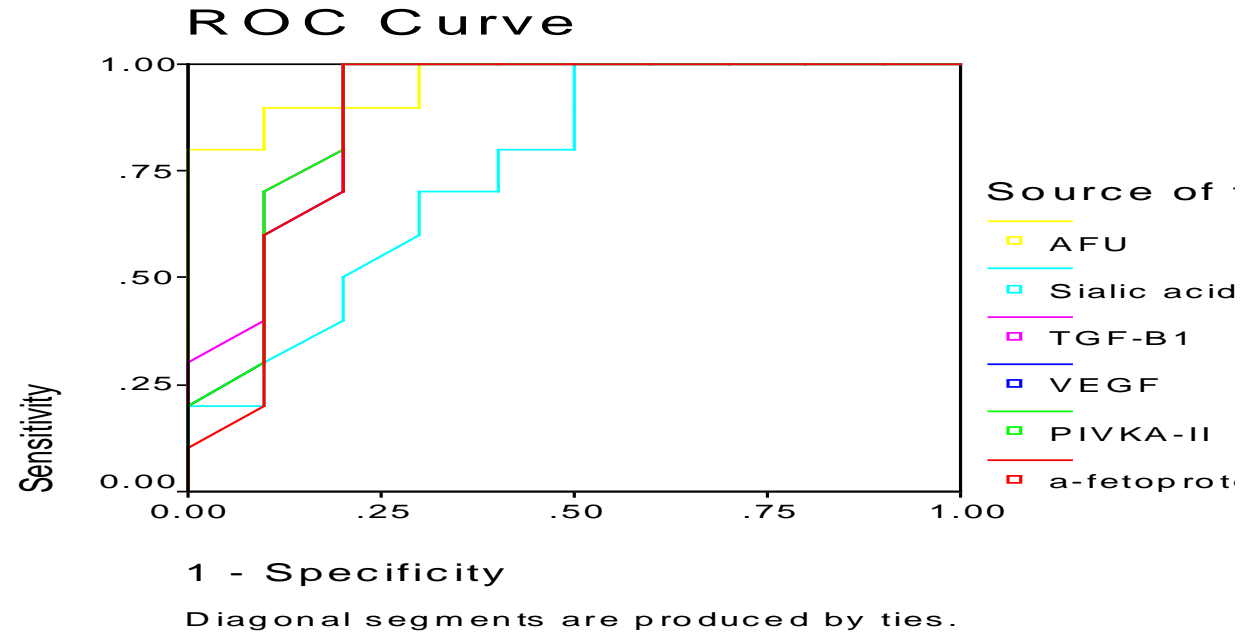

Figure 1: Multiple ROC curves for AFP, PIVKA-II, VEGF, Sialic acid, $\alpha-L-$ fucosidase (AFU) and TGF- $\beta 1$

Table 6: The Cut-off value, sensitivity\%, specificity\%, PPV\%, NPV\%, accuracy $\%$ and AUC for AFP, PIVKA-II, TGF- $\beta 1, V E G F$, sialic acid and AFU.

\begin{tabular}{|c|c|c|c|c|c|c|c|}
\hline & $\begin{array}{c}\text { Cut-off } \\
\text { value }\end{array}$ & $\begin{array}{c}\text { sensitivity } \\
\%\end{array}$ & $\begin{array}{c}\text { specificity } \\
\%\end{array}$ & PPV\% & NPV\% & $\begin{array}{c}\text { Accuracy } \\
\%\end{array}$ & AUC \\
\hline $\operatorname{AFP}(n g / m L)$ & $28 \mathrm{ng} / \mathrm{mL}$ & $80 \%$ & $97 \%$ & $92.3 \%$ & $86.6 \%$ & $90 \%$ & 0.880 \\
\hline $\begin{array}{l}\text { PIVKA-II } \\
(\mathrm{mAU} / \mathrm{mL})\end{array}$ & $\begin{array}{c}12.5 \\
\mathrm{mAU} / \mathrm{mL}\end{array}$ & $80 \%$ & $97 \%$ & $96 \%$ & $86.9 \%$ & $90 \%$ & 0.900 \\
\hline TGF-ß1 (ng/mL) & $32.4 \mathrm{ng} / \mathrm{mL}$ & $76.7 \%$ & $97 \%$ & $95.8 \%$ & $84.7 \%$ & $88.5 \%$ & 0.910 \\
\hline VEGF (pg/mL) & $780 \mathrm{pg} / \mathrm{mL}$ & $96.7 \%$ & $85 \%$ & $82.4 \%$ & $97.1 \%$ & $90 \%$ & 0.890 \\
\hline $\begin{array}{l}\text { Sialic Acid } \\
\text { (mg/dL) }\end{array}$ & 90 mg/dL & $80 \%$ & $78 \%$ & $72.7 \%$ & $77.7 \%$ & $75 \%$ & 0.760 \\
\hline$A F U(\mathrm{nmol} / \mathrm{ml} / \mathrm{h})$ & $\begin{array}{c}443 \\
\mathrm{nmol} / \mathrm{ml} / \mathrm{h}\end{array}$ & $80 \%$ & $90 \%$ & $81.8 \%$ & $88.8 \%$ & $85 \%$ & 0.960 \\
\hline
\end{tabular}

Table 7: Correlations between different parameters in hepatocellular carcinoma group (with and without metastasis).

\begin{tabular}{|l|c|c|}
\hline & $\boldsymbol{p}$-value & r-value \\
\hline serum VEGF and plasma PIVKA-II & $\mathrm{p}=0.012^{*}$ & $\mathrm{r}=-0.594$ \\
\hline Serum AFP and alpha-L-fucosidase & $\mathrm{P}=0.428$ & $\mathrm{r}=0.283$ \\
\hline Serum AFP and sialic acid & $\mathrm{P}=0.692$ & $\mathrm{r}=0.144$ \\
\hline Serum AFP and VEGF & $\mathrm{P}=0.322$ & $\mathrm{r}=0.113$ \\
\hline Serum AFP and TGF-ß31 & $\mathrm{P}=0.106$ & $\mathrm{r}=0.075$ \\
\hline Serum AFP and PIVKA-II & $\mathrm{P}=0.091$ & $\mathrm{r}=0.027$ \\
\hline
\end{tabular}

*Significant 


\section{DISCUSSION}

Hepatocellular carcinoma is one of the most prevalent causes of death in the world. Recently introduced therapeutic approaches for HCC, including percutaneous radiofrequency ablation (RF), transarterial chemoembolization and percutaneous ethanol injection (PEI) have improved the short term prognosis of small sized HCCs. To incorporate the benefit of such advancements into practice, early detection of hepatocellular carcinoma is essential ${ }^{18}$.

Because the majority of HCCs develop in cirrhotic livers, HCC surveillance with AFP and ultrasonography has been recommended for persons with cirrhosis. However, AFP level is insensitive in early diagnosis of the disease $^{\mathbf{1 9}}$. In addition, non specific elevation of serum AFP has been frequently found in patients with non malignant hepatocellular disorders such as acute hepatitis, chronic hepatitis, and liver cirrhosis ${ }^{9}$. Thus, new serologic markers with sufficient sensitivity and specificity are required for early detection of HCC.

In the current study, we aimed at evaluating the diagnostic and prognostic role of AFP, PIVKA-II, VEGF, sialic acid, AFU and TGF- $\beta 1$ in the diagnosis and follow up of patients with hepatocellular carcinoma in an attempt to find a tumor marker with a reasonable sensitivity and specificity for diagnosis of HCC and monitoring patients after therapy.

In the present study, there was a statistically significant difference on comparing the median level of serum
AFP in the HCC groups (with and without metastasis) with the control, the benign focal lesions and the cirrhotic groups $(<0.001)$. Such significant difference between the controls, cirrhotic and HCC groups has been demonstrated in various

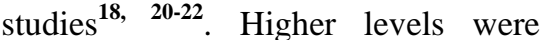
detected in the metastatic HCC with significant difference between that group and the HCC group without metastasis $(\mathrm{p}<0.05)$.

In the current study, the sensitivity of AFP was $80 \%$ and the specificity was $97 \%$ at the cut-off level of $28 \mathrm{ng} / \mathrm{mL}$, PPV of the test was $92.3 \%$, NPV was $86.6 \%$, AUC was 0.880 and the overall accuracy was $90 \%$. The sensitivity of AFP in the present study (80\%) was higher than that reported by Soresi et al. ${ }^{21}$ who found that, at a cut-off value of $30 \mathrm{ng} / \mathrm{ml}$, the sensitivity was $65 \%$ and the specificity was $89 \%$, PPV $74 \%$ and NPV was $79 \%$. Also, He et al ${ }^{22}$ reported that at a cut-off level of 25 $\mathrm{ng} / \mathrm{ml}$, the sensitivity was $68.7 \%$ and the specificity was $86.7 \%$. The reported sensitivities and specificities in different studies could be attributed to the difference in the number of studied population and the methods used for assay.

Although the precise mechanism of plasma PIVKA-II production in HCC is not fully understood, it is widely accepted as a tumor marker for HCC in Japan ${ }^{\mathbf{1 8}}$. It is reported that PIVKA-II is a significant prognostic factor for recurrent $\mathrm{HCC}^{23,}{ }^{24}$. Furthermore, combined elevation of tissue PIVKA-II expression and plasma PIVKA-II levels was found in cases with poor prognosis ${ }^{5}$. In our study, patients with HCC (group 
III\&IV) revealed a significantly higher level of PIVKA-II when compared to the other groups $(\mathrm{p}<$ 0.001). The median plasma PIVKA-II was found to be higher in the metastatic HCC patients than in those without metastasis $(\mathrm{p}<0.05)$.

In the current study, PIVKA-II yielded an AUC of 0.900 , at a cut-off level of $12.5 \mathrm{mAU} / \mathrm{ml}$, the sensitivity was $80 \%$ and the specificity was $97 \%$. In agreement with our finding, Gotoh et al. $^{25}$ who stated that PIVKA-II has a higher AUC than AFP in HCC diagnosis by the ROC analyses, while others $^{\mathbf{2 6}}$ reported less AUC of 0.800 . Different sensitivities and specificities of $62 \%$ and $95 \%$ and $53.3 \%$ and 85.6 $\%$ were reported at a cut-off level of $40 \mathrm{mAU} / \mathrm{ml}$, respectively ${ }^{27,28}$. However, such difference may be attributed to selection of different cutoff value, variation in tumor size, number of masses or to difference in the number of studied cases.

In the present study, the median serum VEGF level was significantly higher in the HCC group without metastasis compared to the group with distant metastasis $(\mathrm{p}<0.001)$. Similarly, Zetter ${ }^{29}$ reported a high VEGF expression in small sized and well differentiated HCCs. He suggested that VEGF plays its most important role in a relatively early stage of the disease. In agreement with these results, Mathonnet et al. ${ }^{30}$ reported that VEGF level gradually decrease with increasing tumor size. El-Assal et al. ${ }^{31}$ reported that HCC nodules larger than $5 \mathrm{~cm}$ in diameter were not more vascular than smaller tumors. On the other hand, Tseng et al. $^{32}$ demonstrated that serum VEGF level in HCC patients showed a positive correlation with tumor size. Furthermore, Poon et al. ${ }^{33}$ reported that high serum level of VEGF was significantly associated with venous invasion and advanced tumor stage. Also, Sun et al. ${ }^{34}$ and Yao et al. ${ }^{35}$ showed that high expression of VEGF is a useful predictor of vascular invasion and metastasis of liver tumors. The discrepancy in serum VEGF level in the metastatic and nonmetastatic HCC groups between our results and the others could be attributed to the different mass size. In our study the diameter of the HCC focal lesions in the metastatic group (group IV) was $>6 \mathrm{~cm}$, which may compress the blood vessels resulting in low serum VEGF level.

Transforming growth factor- $\beta 1$ (TGF- $\beta 1$ ) is a potent cytokine involved in a number of different functions such as epithelial mesenchymal transition, tissue morphogenesis, angiogenesis, and hence tumor progression, invasion, and metastasis. In liver tissues, TGF$\beta 1$ has a profibrotic activity, stimulating extracellular matrix production, and is involved in the pathogenesis of liver cirrhosis. In other tissues, it stimulates integrin expression in different types of both normal and cancer cells ${ }^{36}$. In the present study, the median plasma TGF- $\beta 1$ level was found to be significantly higher in the HCC groups when compared to control, benign and cirrhotic groups $(\mathrm{p}<0.001)$. This in agreement with Gianluigi et al. ${ }^{36}$ and Anna. et al. ${ }^{37}$ who reported that increased secretion of TGF- $\beta 1$ by cancer cells is thought to facilitate tumor progression by indirect means, such as suppression of immune 
surveillance and stimulation of tumor stroma.

Sialic acid, a class of important ketoses that contain nine carbon atoms, is an acetylated derivative of neuraminic acid (2-keto-5-amino-3, 5dideoxy-D-nonulosonic acid). The unique structural features of this molecule, which includes a negative charge owing to a carboxyl group, enable it to play an important role in cellular functions, such as cell to cell recognition and transformation to malignancy ${ }^{\mathbf{1 0}}$. As sialic acid lacked tumor specificity, it might contribute towards the early detection of tumor progression and metastasis during both therapy and follow-up. It was concluded that total serum sialic acid level reflected the development of malignancy and should be considered as a supportive evidence of being tumor marker for many malignant conditions $^{\mathbf{1 0}}$. In the present study, patients with malignancy revealed a significantly higher level of sialic acid when compared to the other groups $(\mathrm{p}<0.001)$. The median serum sialic acid was found to be higher in the metastatic HCC patients than in those without metastasis $(\mathrm{p}<0.001)$. This is in agreement with Cai Wen-Xiu et al. ${ }^{38}$ who reported that most patients with HCC have an elevated concentration of serum total sialic acid, and determination of this marker yields high diagnostic values that differentiate between HCC and benign hepatobiliary diseases.

In the current study, the sensitivity of sialic acid was $80 \%$ and the specificity was $78 \%$ at the cut-off level of $90 \mathrm{mg} / \mathrm{dL}$, PPV of the test was $72.7 \%$, NPV was $77.7 \%$, AUC was 0.760 and the overall accuracy was $75 \%$. The sensitivity of sialic acid in our study was different from that reported by Cai Wen-Xiu et al. ${ }^{38}$, who reported that at a cut-off value of $63 \mathrm{mg} / \mathrm{dL}$, the sensitivity was $70 \%$ and the specificity was $80 \%$, PPV $75 \%$ and NPV was $80 \%$ and by using the cut-off value of $63 \mathrm{mg} / \mathrm{dL}$, the obtained sensitivity and specificity were lower than that obtained by Cai Wen-Xiu et al. ${ }^{38}$. The differences in the reported sensitivities and specificities could be attributed to the difference in the number of studied population and the methods used for assay.

Alpha-L-fucosidase (AFU) is enzyme belongs to the family of hydrolases, specifically those glycosidases that hydrolyse $\mathrm{O}$ - and $\mathrm{S}$ glycosyl compounds. The systematic name of this enzyme class is alpha-Lfucoside fucohydrolase. It participates in $\mathrm{N}$-glycan degradation and glycan structures - degradation. ${ }^{12,39}$

In the present study, patients with malignancy revealed a significantly higher level of AFU (group III and IV) when compared to the other groups $(p<0.001)$. the results of the present study were in agreement with Deugnier et al. ${ }^{11}$ who reported a significant increase in serum $\alpha$-Lfucosidase activity among patients with hepatocellular carcinoma as compared either to patients with cirrhosis or to healthy control subjects. The median serum AFU was found to be higher in the metastatic HCC patients than in those without metastasis $(p<0.05)$. Also, our results were in agreement with Marotta et al. ${ }^{40}$ who stated that hepatocellular carcinoma is able to release into the blood stream a significant amount of 
alpha-L-fucosidase, which correlates with the size of the tumor and provides a useful marker in the follow-up of patients treated for HCC.

In the present study, AFU yielded an AUC of 0.96, at a cut-off level of $443 \mathrm{nmol} / \mathrm{mL} / \mathrm{h}$, the sensitivity was $80 \%$, the specificity was $90 \%$, PPV was $81.8 \%$, NPV was $88.8 \%$ and the accuracy was $85 \%$. In agreement with our finding, Giardina et al. ${ }^{39}$ who stated that When $443 \mathrm{nmol} / \mathrm{ml} / \mathrm{h}$ is taken as the cut-off value; alpha-Lfucosidase sensitivity and specificity were $76 \%$ and $90.9 \%$, respectively.

In the current study, a statistically significant lowering of the median blood levels of all parameters six months after ablation therapy was noticed. Similarly, Ikoma et al. ${ }^{\mathbf{4 1}}$ reported that plasma PIVKA-II level was normalized in $67 \%$ of patients after treatment and that combined measurement of PIVKA-II with AFP is useful for monitoring recurrence of HCC after treatment. Sheen et al. ${ }^{42}$ found that VEGF is a significant biological indicator of the invasiveness of postoperative recurrence. Also, Cai Wen-Xiu et al. $^{38}$ reported that measurement of sialic acid is useful for monitoring recurrence of HCC after treatment.

In the current study a statistically significant negative correlation was found between serum VEGF and plasma PIVKA-II in the HCC groups (with and without metastasis) (Table 7). Such correlation was not found between serum AFP and the other markers. No correlation was found between AFP level and alpha-Lfucosidase activity, AFP and sialic acid level, AFP and VEGF, AFP and PIVKA-II and AFP and TGF- $\beta 1$ (p
$=0.428,0.692,0.322,0.091$ and 0.106 respectively) (Table 7). These findings confirm those of lshii et al. ${ }^{\mathbf{1 8}}$ and Cui et al. $^{\mathbf{2 8}}$ who found no correlation between AFP level and PIVKA-II level in the HCC patients and Shirai et al. ${ }^{43}$ who could not find a significant correlation between TGF- $\beta 1$ and AFP level in HCC patients. Also, serum AFP and AFU activity were independent with no correlations between them as evidenced by Cai Wen-Xiu et al. ${ }^{38}$.

In the present study, combination of two markers or more improved both sensitivity and specificity as combination of AFP and PIVKA-II yielded a sensitivity and specificity of 93.3\% and $98.2 \%$ and for AFP with TGF- $\beta 1$, the sensitivity and specificity were $87.5 \%$ and $99 \%$, respectively. By combined measurement of AFP and AFU, the sensitivity and specificity were $95 \%$ and 98\%, respectively. While combined measurement of both AFP and sialic acid gave sensitivity 89 and specificity $98 \%$ as three of the twenty patients with HCC who had AFP level below the cut-off value, had positive results in AFU and another one had a positive result in sialic acid. Therefore, combined measurement of serum AFP and AFU, AFP and PIVKA-II, AFP with TGF- $\beta 1$ or AFP and sialic acid is of practical significance in diagnosis of hepatocellular carcinoma.

In the current study, the main purpose of using combined measurement of tumor markers is to eliminate the false negative and false positive results as reported by many authors $^{10,18}$. After reviewing our results as well as those of others, the 
question on the usefulness of combining markers in assessing early diagnosis of malignant liver disease is raised. Our data support the highly significant value of combined markers as a screening tool for early diagnosis in susceptible individuals. Therefore, combined determination of the studied serological markers could be used as a highly valuable tool for screening and diagnosis of hepatocellular carcinoma. They could also be used as prognostic markers decreasing the need for more invasive procedures. The combined use of easy and cheap serological markers with sufficient sensitivity and specificity is of great value in follow up of HCC patients as by combined measurement of $\alpha$-fetoprotein and $\alpha$ L-fucosidase or $\alpha$-fetoprotein and sialic acid. Also, according to our results these markers offer a potential for using them for follow up after treatment.

\section{REFERENCES}

1. DiBisceglie A.M. (2004): Issues in screening and surveillance for hepatocellular carcinoma. Gastroenterology 127(5 Suppl., 1):S104-107.

2. Ulmer S.C. (2000): Hepatocellular carcinoma. A concise guide to its status and management. Postgrad. Med., 107(5):117-124.

3. Duffy M.J. (2001): Clinical uses of tumor markers: A critical review. Crit. Rev. Clin. Lab. Sci., 38(3): 225-262.

4. Tsai J.F., Jeng J.E. and Ho M.S. (1995): Clinical evaluation of serum alpha fetoprotein and circulating immune complexes as tumor markers of hepatocellular carcinoma. Br. J. Cancer 72(2): 442-446.

5. Tang W., Kokudo N. and Sugawara Y. (2005): Desgamma-carboxyprothrornhin expression in cancer and/or noncancer liver tissues: Association with survival of patients with resectable hepatocellular carcinoma. Oncol. Rep., 13(1): 25-30.

6. Fuhrmann B.E., Ma M.N. and Rubbia B.L. (2000): Elevated levels of angiogenic cytokines in the plasma of cancer patients, Int. J .Cancer 85(1):40-45.

7. Zhang H., Ozaki I. and Mizuta T. (2004): Transforming growth factor-ß1- induced apoptosis is blocked by beta 1 -integrinmediated mitogen-activated protein kinase activation in human hepatoma cells. Cancer Sci., 95(11):878-686.

8. Cheng P.L., Chang M.H. and Chao C.H. (2004): Hepatitis C viral proteins interact with Smad3 and differentially regulate TGFbeta/Smad3 mediated transcriptional activation. Oncogene 23(47): 7821-7838.

9. Song B.C., Chung Y.H. and Kim J.A. (2002): Transforming growth factor Beta-1 as a useful serologic marker of small hepatocellular carcinoma. Cancer 94(1): 175-180.

10. Isitmangil T., Isitmangil G. and Budak Y. (2001): Comparison of serum and bronchoalveolar lavage fluid sialic acid levels between malignant and benign lung diseases. B.M.C. Pulm. Med., (1): 1-4. 
11. Deugnier Y., David V. and Brissot P. (1984): Serum $\alpha$-Lfucosidase: a new marker for diagnosis of primary hepatic carcinoma? Hepatology 4(5):889892.

12. Zielke K., Okada S. and O’Brien J. (1972): Fucosidosis: diagnosis by serum assay of alpha-L-fucosidase. J. Lab. Clin. Med., 79:164-169.

13. Hess W.C. and Papodopoulos N.H. (1957): A high precision selective determination method for $\mathrm{N}$ - acetyl-neuraminic acid in human serum. Ann. Biochem., 170(1): 140-144.

14. Uotila M., Ruoslahti E. and Engvall E. (1981): Two-site sandwich enzyme immunoassay with monoclonal antibodies to human alpha-fetoprotein. J. Immunol. Methods 42: 11-15.

15. Meguro $M$. and Yamada $K$. (1982): A simple and rapid test for PIVKA-II in plasma. Thromb. Res., 25:109-113.

16. Keyt B.A., Berleau L.T., Nguyen H.V., Chen H., Heinsohn H., Vandlen R. and Ferrara N. (1996): The carboxyl-terminal domain (111165) of vascular endothelial growth factor is critical for its mitogenic potency. J. Bio. Chem., 271(13):7788-7795.

17. Massagué J. (1990): Mediators of TGF- $\beta$ actions. TGF- $\beta$ receptors, and TGF-ß1 binding proteoglycans. Ann. N. Y. Acad. Sci., 593:59-72.

18. Ishii M., Gama $H$. and Chida N. (2000):

Simultaneous measurements of serum alphafetoprotein and protein induced by vitamin $\mathrm{K}$ absence for detecting hepatocellular carcinoma. South Tohoku district study group. Am. J. Gastroenterology 95(4): 10361040.

19. He Y.M., Wang X.Y. and Gao S.D. (2005): Ultrasound-guided fine needle biopsy of intrahepatic nodules and low elevation of AFP in early diagnosis of hepatocellular carcinoma. Hepatobiliary Pancreat. Dis. Int., 4(1): 50-54.

20. Hamamura K., Shiratori Y. and Shiina S. (2000): Unique clinical characteristics of patients with hepatocellular carcinoma who present with high plasma desgamma-carboxy prothrombin and low serum alpha-fetoprotein. Cancer 88(7):1557-1564.

21. Soresi M., Magliarisi C. and Campagna P. (2003): Usefulness of alpha fetoprotein in the diagnosis of hepatocellular carcinoma. Anticancer Res., 23(2C):1747-1753.

22. He M., Shi Y.R. and Zou W. (1996): Combined assay of serum AFU and AFP in patients with primary hepatic carcinoma. Chin. J. Clin. Oncol., 23(1):21-23.

23. Nagaoka S., Yatsuhashi $H$. and Hamada H. (2003): The desgamma-carboxy prothrombin index is a new prognostic indicator for hepatocellular carcinoma. Cancer 98 (12):26712677.

24. Kaibori M., Matsui Y. and Yanagida H. (2004): Positive status of alpha fetoprotein and des-gamma-carboxy prothrombin: Important prognostic factor for 
recurrent hepatocellular carcinoma. World J. Surg., 28(7): 702-707.

25. Gotoh M., Nakatani T. and Masuda T. (2003): Prediction of invasive activities in hepatocellular carcinomas with special reference to alpha fetoprotein and des-gammacarboxyprothrombin. Jpn. J. Clin. Oncol., 33(10): 522-526.

26. Marrero J.A., Su G.L. and Wei W. (2003): Des-gamma carboxyprothrombin can differentiate hepatocellular carcinoma from nonmalignant chronic liver disease in American patients. Hepatology 37(5): 11141121.

27. Mita Y., Aoyagi Y. and Yanagi M. (1998): The usefulness of determining des gamma-carboxy prothrombin by sensitive enzyme immunoassay in the early diagnosis of patients with hepatocellular carcinoma. Cancer 82(9):1643-1648.

28. Cui R., He J. and Zhang F. (2003): Diagnostic value of protein induced by vitamin $\mathrm{K}$ absence (PIVKAII) and hepatoma-specific band of serum gamma-glutamyl transferase (GGT-II) as hepatocellular carcinoma markers complementary to alphafetoprotein. Br. J. Cancer 88 (12): 1878-1882.

29. Zetter B.R. (1998): Angiogenesis and tumor metastasis. Annu. Rev. Med., 49: 407- 424.

30. Mathonnet M., Descottes B. and Valleix D. (2006): Vascular endothelial growth factor in hepatocellular carcinoma and surrounding cirrhotic liver tissues. World J. Gastroenterology 12(5): 830-831.

31. El Assal O.N., Yamanoi A. and Soda Y. (1998): Clinical significance of microvessel density and vascular endothelial growth factor expression in hepatocellular carcinoma and surrounding liver: Possible involvement of vascular endothelial growth factor in the angiogenesis of cirrhotic liver. Hepatology 27(6):1554-1562.

32. Tseng C.S., Lo H.W. and Chen P.H. (2004): Clinical significance of plasma D-dimer levels and serum vascular endothelial growth factor levels in patients with hepatocellular carcinoma. Hepatogastroenterology 51(59):1454-1458.

33. Poon R.T., Ho J.W. and Tong C.S. (2004): Prognostic significance of serum vascular endothelial growth factor and endostatin in patients with hepatocellular carcinoma. Br. J. Surg., 91(10): 1354-1360.

34. Sun X.Y., Wu Z.D. and Liao X.F. (2005): Tumor angiogenesis and its clinical significance in pediatric malignant liver tumor. World J. Gastroenterology 11(5):741-743.

35. Yao D.F., Wu X.H. and Zhu Y. (2005): Quantitative analysis of vascular endothelial growth factor, microvascular density and their clinicopathologic features in human hepatocellular carcinoma. Hepatobiliary Pancreat. Dis. Int., 4(2): 220-226. 
36. Gianluigi G., Emilia F. and Felice M. (2002): Transforming Growth Factor- $\beta 1$ Triggers Hepatocellular Carcinoma Invasiveness via $\alpha 3 \beta 1$ Integrin. Am .J. Pathol., 161(1): 183-193.

37. Anna B., Angiola B., Marco G. and Emirena G. (2008): Transforming growth factor $ß 1$ and CD105 promotes the migration of hepatocellular carcinoma- derived endothelium. Cancer Res., 68(20): 8626-8634.

38. Cai Wen-Xiu, Zheng $H$. and Sheng J. (1998): Combined measurement of serum tumor markers in patients with hepatocellular carcinoma. World J. Gastroenterology 4(2):181-182.

39. Giardina M., Matarazzo $M$. and Varriale A. (1992): Serum Alpha- L-Fucosidase: A Useful Marker in the Diagnosis of Hepatocellular Carcinoma. Cancer 70:1044-1048.

40. Marotta F., Chui D.H. and Safran P. (1991): Serum $\alpha$-Lfucosidase: A more sensitive marker for hepatocellular carcinoma. Digestive diseases and sciences 36(7): 993-997.

41. Ikoma J., Kaito $M$. and Ishihara T. (2002): Early diagnosis of hepatocellular carcinoma using a sensitive assay for serum des-gammacarboxyprothrombin: A prospective study. Hepatogastroenterology 49(43): $235-238$.

42. Sheen I.S., Jeng K.S. and Shih S.C. (2005): Clinical significance of the expression of isoform 165 vascular endothelial growth factor mRNA in noncancerous liver remnants of patients with hepatocellular carcinoma. World J. Gastroenterology 11(2): 187192.

43. Shirai Y., Kawata S. and Tamura S. (1994): Plasma transforming growth factor-ß1 in patients with hepatocellular carcinoma: Comparison with chronic liver diseases. Cancer 73(9):2275-2279.

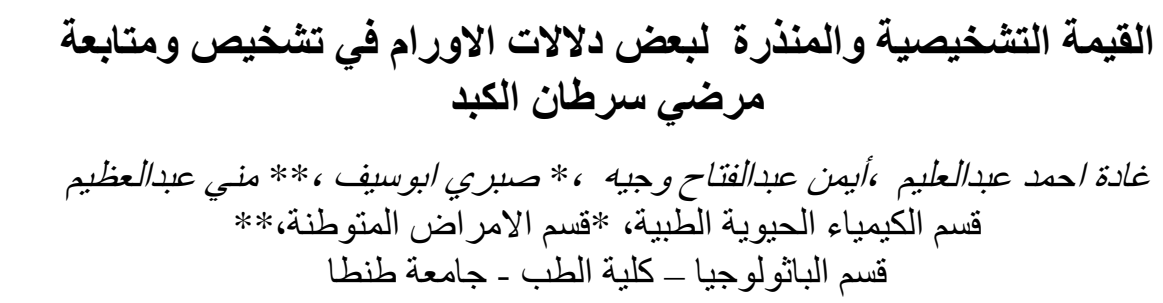

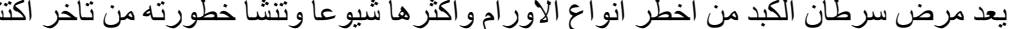

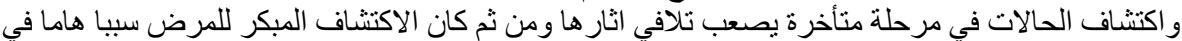

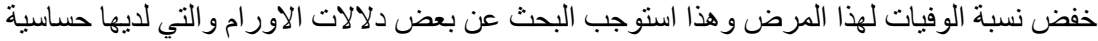

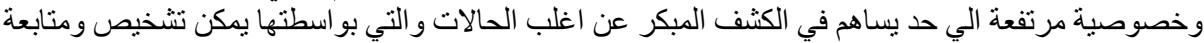

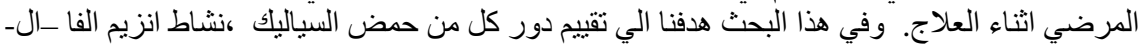

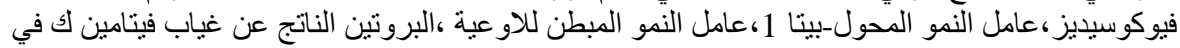




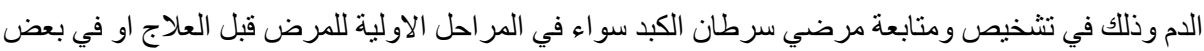

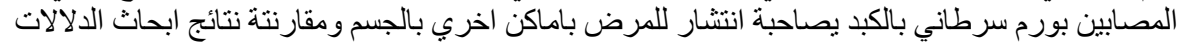

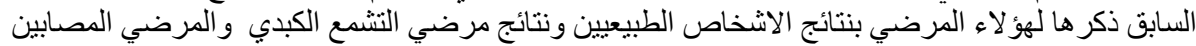

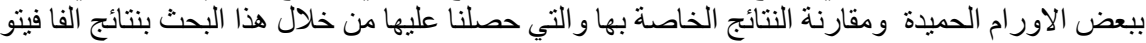

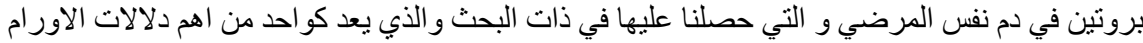

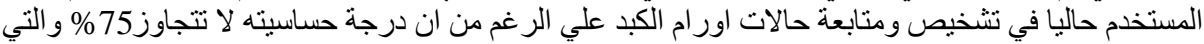

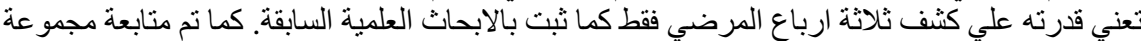

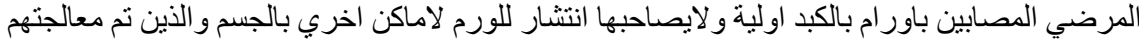

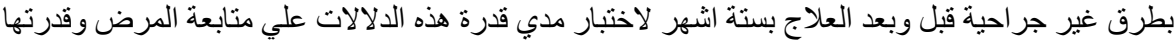
علي الانذار المبكر عند حدوث أي مضاعفات.

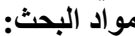

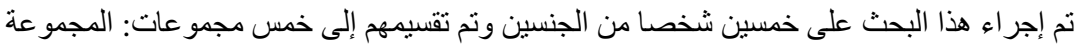

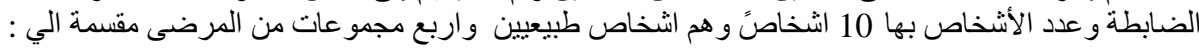

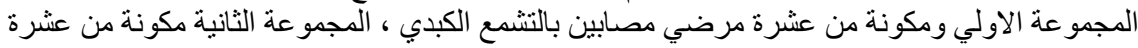

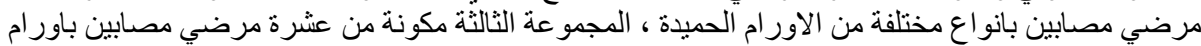

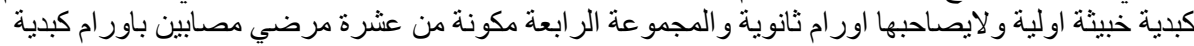

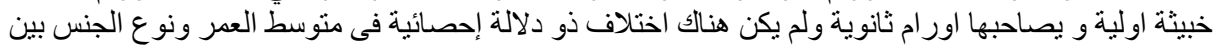

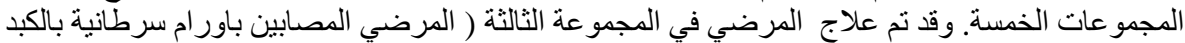

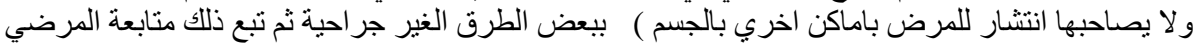
بقياس نفس دلالات الاورام السابقة بعد العلاج بستة اشهر وبعد التأكد من تلاشي الورم باستخدام الاشعة

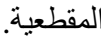

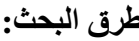

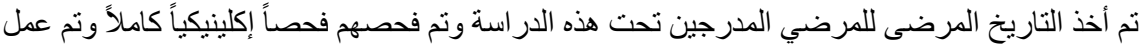

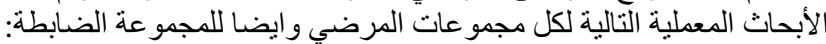

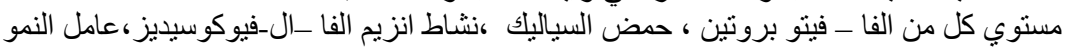

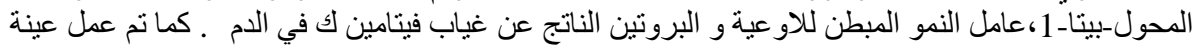

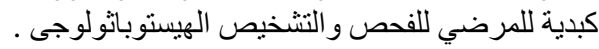

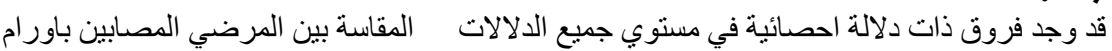
نتائج البحث:

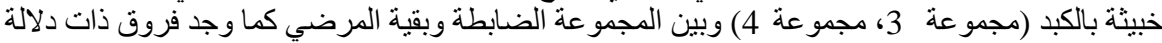

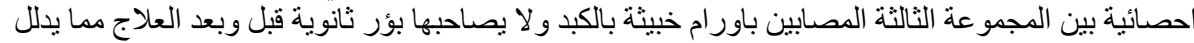

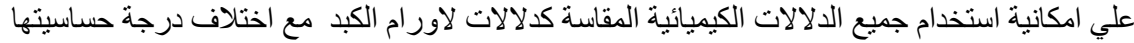

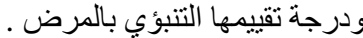

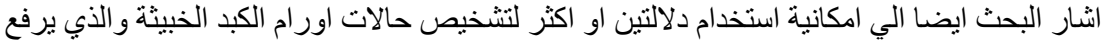

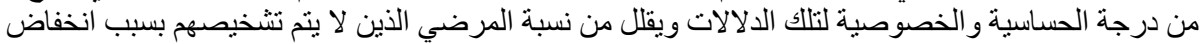

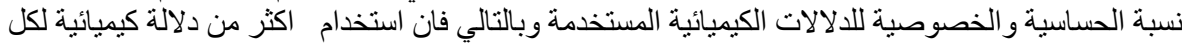

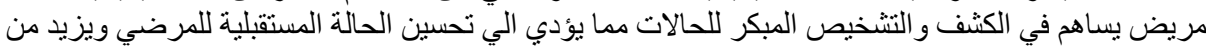
الفترة التي يحياها المريض في سلام . 